\title{
Labirintos, Tergiversações e Enganações: reflexões sem dor sobre o debate político brasileiro atual
}

Bolívar Lamounier ${ }^{1}$

Resumo

Este artigo reflete sobre as manifestações de Junho de 2013 e delineia três correntes de pensamento algo fantasiosas que permeiam o debate público brasileiro: as utopias da intervenção militar, da democracia 'direta' e a de uma democracia representativa extremamente idealizada. Ao final, fazem-se algumas considerações de ordem geral sobre a reforma política e o sistema eleitoral no Brasil.

Palavras-chave: Democracia, Democracia Direta, Democracia Representativa, Reforma Política, Sistema Eleitoral.

\section{Labyrinths, Tergiversations and Deceptions: reflections without pain on the current Brazilian political debate}

\section{Abstract}

This paper examines the protests of July 2013, outlining three deluded currents of thought that are commonplace in Brazil's public debate: the utopias of military intervention, 'direct' democracy, and idealized representative democracy. In the end, we present some general thoughts about political reform and the electoral system in Brazil.

Key-words: Democracy; Direct democracy; Representative democracy; Political reform; Electoral system.

\footnotetext{
${ }^{1}$ Doutor em Ciência Política.
} 


\section{I.}

Um fator que me parece dificultar atualmente a discussão política é uma combinação de maniqueísmo com distinções rombudas como a dicotomia esquerda x direita. Um se diz "de esquerda" e se arvora em porta-voz do "bem", o outro proclama-se "de direita" e se diz do bem também, e assim la nave va.

Comecemos pelo óbvio: a realidade política é sumamente complexa; nossas palavras servem para formular conceitos e hipóteses, para tentar abarcá-la, mas nossa compreensão será sempre insuficiente; as palavras (conceitos e hipóteses) não são chapadas, como se existissem numa superfície plana; são complexas, poliédricas, multidimensionais, repletas de ambiguidades.

Vejamos alguns exemplos: para um militante de esquerda, "empresário" é um palavrão que só serve para designar uma das faces do mal; para um economista ou para uma pessoa apenas interessada no que os dicionários dizem, empresário é um agente econômico (entre outros). "Conservador", para o militante, é sinônimo de direitista, reacionário, burguês etc. Para uma pessoa comum, é o quê? Pelo dicionário, é uma pessoa que prefere conservar o presente, mesmo considerando-o defeituoso, que embarcar numa aventura ou apoiar uma política que certamente redundará em coisa pior.

Realmente, no plano da linguagem política, o maniqueísmo e o desleixo com as palavras devem ser vistos como problemas que fatalmente resultarão em outros problemas. Modos confusos de pensar, bons para aumentar a confusão. Mas não são os únicos. À confusão pode-se chegar por vários caminhos. Cogitar de modo obscuro uma solução para um dado problema, sem definir direito o problema e sem destrinchar a própria (suposta) solução é outra possibilidade. Tende a produzir calor sem aumentar ou mesmo diminuindo a luz. 
Suponhamos que o "problema" é o Brasil atual (ou o Brasil antes das manifestações, quando o pessimismo era muito maior): corrupção, incompetência, desperdício de dinheiro público, políticos abomináveis, casas representativas que nada representam. E calcemos aqui as nossas botas de sete léguas: admitamos que o "problema" está definido com clareza. Aqui, como se verá a seguir, quem adentra o recinto é um figura que imaginamos conhecer bem: a utopia.

Aparece um primeiro cidadão - não importa se de direita, esquerda, de baixo ou do alto - e exclama: a solução é uma intervenção militar! Os militares precisam voltar imediatamente ao poder!

Na realidade, "militares" é a única palavra relativamente clara nesse enunciado. Relativamente. Para os militares "voltarem", presume-se que terão um líder, um chefe, o que na prática significa um ditador. 0 cidadão que os conclama a voltar obviamente pressupõe que esse chefe será um sujeito esclarecido, equilibrado, competente, ético etc. Um estadista em uniforme verde-oliva. E que terá apoio para governar, dos próprios militares e da maioria da sociedade, ça va sans dire. Quer dizer, o apelo à intervenção traz implícito um wishful-thinking cavalar: o ditador só terá qualidades, nenhum defeito. Formidável.

Ele também pressupõe que "voltar" é como ir à esquina chupar um picolé. Os militares não encontrarão resistência, nem na intervenção em si nem nos meses seguintes. Mas perguntar não ofende: e se tiverem? Prendem e arrebentam? Prendem quantos, mais ou menos? Os mortos e desaparecidos serão $600 \mathrm{ou}$ 700 em 21 anos, numa população de 90 milhões, como aconteceu no Brasil, ou cerca de 15 mil, como ocorreu na Argentina, um país cuja população é cerca de um terço da brasileira? Mesmo aqui, a título preliminar, há outros "detalhes" a considerar. Por exemplo: na era pré-Internet, as intervenções militares geralmente recorriam ao estado de sítio, um instrumento jurídico 
que permitia interceptar as comunicações postais e telefônicas, revistar pessoas e casas etc. Como será aplicar o estado de sítio na era da internet? Vai-se suspender toda a rede de comunicações via celulares, computadores etc? Se sim, anotem: quem faz isso é a China; um país da América Latina que siga esse caminho arranjará sarna para se coçar durante 50 anos.

Não quero me estender, mas resta uma indagação importante. Se os militares voltarem, presumivelmente vão mexer na economia; não há como reorganizar o país sem mexer nela. Então eles voltam, para fazer o quê, exatamente? Intervêm mais, estatizam mais, tabelam salários e preços? Ou fazem o contrário: tentam manter-se à margem, privatizam e tentam restaurar a confiança dos agentes econômicos internos e externos no mercado e no arcabouço jurídico que o regula?

Outra "solução" diuturnamente aventada é a "democracia direta”. Nesta expressão, a única coisa clara é que o "povo" terá mais presença, mais participação, será mais ouvido. OK, suponhamos que isso está claro. A expressão em si não é propriedade da esquerda, da direita ou do centro. É uma utopia, simplesmente. Os cidadãos que a cogitam querem se livrar da "representação", este é o ponto que os une. Os mais realistas e sinceros dizem que a ideia ainda não está madura, e que será realizada, quando o for, via internet. De suas casas, milhões e milhões de pessoas decidirão sobre as questões da agenda pública como melhor lhes pareça. Estes, como disse, são os mais sinceros.

Para outros, "democracia direta" significa entregar uma enorme quantidade de poder aos chamados "movimentos sociais". Para designar essa revolução institucional - porque é disso que se trata: uma revolução institucional- eles recorrem a uma variedade de termos, por exemplo o abominável "empoderar". Argh! Empoderar, uma tradução mal ajambrada do inglês "empower", significa, como assinalei, transferir um monte de poder para organizações sindicais, clericais, estudantis etc; todas ligadas ao 
PT e aos pequenos partidos de esquerda, mas isto é um detalhe. Tais organizações passarão então a exercer aquele pedação de poder, decidindo "diretamente" sobre uma variedade de assuntos. E como será essa participação "direta” no processo decisório? Elementar, Watson: os líderes dos "movimentos sociais" participarão de reuniões e decidirão por eles. Ou seja: REPRESENTANTES decidirão "diretamente" por eles. É ou não é uma obra prima do "me engana que eu gosto"?

Poderíamos prosseguir esta discussão ad infinitum, mas as questões em jogo são no fundo muito simples. Primeiro, de "direta" essa democracia tem muito pouco, ou nada; seus sujeitos serão representantes; os "movimentos sociais" tomarão o lugar das instituições representativas tradicionais por meio de uma megatransferência de poder para o "povo", quero dizer, para si mesmos. A diferença é pois que os "nossos" representantes deixarão de ser ELETIVOS no sentido amplo do termo, eleitos pela totalidade dos cidadãos habilitados a votar. Em segundo lugar, a suposta legitimidade de tais representantes para decidir em nome de quem quer que seja. De fato, que superioridade prática ou legitimidade moral têm sindicatos, movimentos reivindicativos, igrejas etc. para encarnar os interesses gerais de uma coletividade, inclusive os interesses de indivíduos que não rezam pela cartilha de tais sindicatos, movimentos ou igrejas?

II.

Na primeira parte deste texto eu tentei pôr em evidência certas imprecisões e ingenuidades que geralmente se associam tanto ao recorrente apelo à intervenção militar como as esperanças depositadas na 'democracia direta'.

Nesse post eu vou propor um exercício semelhante, mas a respeito da própria democracia representativa. Mas será que esta proposta faz sentido? Como podem ser utópicas as expectativas 
sobre um modelo que existe há tanto tempo nos quatro cantos do mundo? A resposta é muito simples. 0 que tentei esclarecer no post de ontem e vou novamente tentar neste tem menos a ver com as realidades políticas que com o nosso modo de vê-las, ou seja, com certos pressupostos e defeitos de raciocínio que contaminam o nosso esforço em compreendê-las e com anseios ou ideais que projetamos sobre elas à medida que lutamos por aprimorá-las.

Uma pessoa perfeitamente realista nas coisas práticas da vida mas inconsciente dos conceitos e pressupostos que utiliza pode ser levada a pensar de forma irrealista sobre política. 0 mesmo acontece com pessoas que imaginam a política como um domínio totalmente subjetivo e maleável sobre o qual podemos imprimir os nossos desejos ou nossa visão particular. Em semelhante equívoco só em também ocorrer pessoas profundamente imbuídas da noção aristotélica da política como a busca do "bem comum", não se dando conta de que tal formulação diz respeito ao que "deveria ser", não ao que "é"; sem esquecer que o "bem comum" pode assumir feições vastamente diferentes entre diferentes pessoas.

Voltando então à democracia, a questão chave a destrinchar parece-me ser a do Legislativo. Ninguém ignora que os Legislativos de dezenas de países são vistos com extrema severidade por suas respectivas sociedades, e não sem razão. Tal atitude se deve em parte a problemas reais: corrupção, privilégios abusivos etc etc. Mas deve-se também, em parte, à maior transparência do Legislativo em comparação com os outros dois Poderes. Diferentemente do Judiciário e do Executivo, o Legislativo é um poder aberto. Qualquer coisa esquisita que nele aconteça, mesmo não envolvendo malfeito algum, será noticiada em tempo real e será martelada por semanas a fio pela imprensa. Um deputado que cometa uma patacoada verbal ou empregue termos demasiado agressivos num debate estará no lucro se não for pintado como a própria encarnação das mazelas brasileiras desde Pedro Álvares 
Cabral. Dita entre quatro paredes por um juiz ou por um ministro, a mesma patacoada não renderá toda essa censura, pela singela razão de que ninguém tomará conhecimento do fato.

No Legislativo, com efeito, praticamente tudo o que ocorre nas comissões e tudo o que acontece no plenário acontece EM PÚBLICO. Nem sempre foi assim. Na Inglaterra, durante o século 18, a divulgação das atividades internas do Legislativo era proibida. Duas coisas mudaram: tal proibição tornou-se impensável em qualquer país e a capacidade técnica e jornalística da imprensa cresceu um milhão de vezes. Não estará nessa dupla mudança Uma parte da explicação para o mau conceito em que os legislativos são tidos?

Recapitulemos: o descrédito dos legislativos deve-se em parte a problemas reais, objetivos, inegáveis, e em parte ao fato de ele ser o mais transparente dos poderes, portanto o mais devassado pela poderosa imprensa da era atual. A terceira parte da explicação parece-me dever-se a certas concepções, expectativas e anseios que nós projetamos sobre a esfera política em geral e sobre os legislativos em particular. Indignado com o comportamento dos parlamentares, o cidadão reage com um "dever" ser: um receituário normativo. Quer um Congresso constituído só de gente honesta, competente e altruísta, dedicada ao bem comum. Como criticá-lo, se ele deseja o melhor? 0 problema, evidentemente, é que este discurso na prática equivale a lavar as mãos. Ao martelar continuamente a tecla normativa, o cidadão se desprepara para compreender o mundo real e atuar sobre ele. A política e o Legislativo existem no mundo real, não fora dele; não no deserto, onde só vive o ermitão. Não aceitar o mundo real da política é vê-lo pelos olhos de Santo Agostinho: os bons pensam no céu e deixam o mundo terreno para os maus. Que significa aceitar o mundo real? Significa "acomodar-se" a ele, como às vezes se afirma? De forma alguma. Eu penso o contrário: acomoda-se a ele na prática quem dele foge do plano do conhecimento. 
No plano do conhecimento, legislativos existem para representar e tentar equacionar os múltiplos e contraditórios interesses que se digladiam na sociedade. Representar, neste sentido, implica insistir, pressionar, fazer-se levar em conta como porta-voz dos representados, sejam eles um grupo social, um setor, uma região ou os adeptos de uma pauta de valores. Implica pelejar para que o interesse deles seja contemplado na legislação e passe a ter respaldo na força do Estado. Para isto - e sob pena de trair o interesse de seus representados- o deputado ou senador precisa tornar efetiva a fração de poder que teoricamente lhe cabe - e mais, se possível. Nesta questão nevrálgica encontra-se possivelmente uma das principais raízes da estranheza com que o cidadão comum observa a vida política e o parlamento.

De fato, como antes assinalei, a hostilidade aos legislativos e à política não se explica inteiramente por fatores reais. Em todo o mundo, talvez devido a frustrações da vida cotidiana ou a uma sensação de exclusão e impotência- não posso me deter nessa questão- milhões de pessoas descarregam muito fel na esfera pública, vituperando comportamentos que lhes parecem incômodos, levianos, inúteis, agressivos ou antiéticos. Eu conjeturo que essa tendência possa se dever a um desconforto em relação a certas "exterioridades" do poder, tais como, as disputas dos políticos pelo controle de seus próprios partidos e por lugares nas chapas eleitorais; as campanhas e as promessas, não raro vagas ou inexequíveis; as táticas de combate parlamentar, só inteligíveis a quem conheça o emaranhado dos regimentos internos.

Na democracia, mais que em outros regimes políticos, o poder é obtido através de uma longa série de pequenos investimentos políticos: de uma acumulação que começa na capacidade inicial de se eleger, passa pelo desempenho em determinados cargos, pela participação em comissões, pela exposição à mídia e o reconhecimento público etc etc. Tudo faz crer que o cidadão se incomode muito com essa sucessão de atividades e embates pautados tão somente pela necessidade de acumular poder. A entrada e a pro- 
gressão na carreira política exigem de quem a pratica, sobretudo daquele que nela ingressa com poucos recursos financeiros e pouco prestígio, um incessante investimento em poder. Mas a acumulação de poder é sempre lenta, paulatina e se faz por "nacos", inch-by-inch. 0 novato dança conforme a música. Ora é um puxa-saco, ora se comporta de forma arestosa; e não tem como se pôr à margem daquele microcosmo carregado de vaidades, intrigas e sentimentos nem sempre encantadores. Milhões de cidadãos que acompanham pela imprensa as informações desse pequeno grand monde reagem com desagrado, projetando na esfera política todo o azedume de que possam dispor. Esta afirmação é especialmente verdadeira no que tange ao Legislativo. Pode-se observar que, na transmissão por TV de investigações de corrupção, práticas parlamentares legítimas e necessárias, com suas questões de ordem, pedidos de verificação de quorum, formas de obstrução etc. frequentemente suscitam reações negativas da parte dos telespectadores. Eis a ironia: o complexo sistema de regras em que se baseia o funcionamento do Legislativo- um grande feito civilizatório da democracia e do mundo moderno-, retira da política muito de seu drama, envolve-a numa atmosfera de mesquinharia e acaba contribuindo para a indiferença e até para a hostilidade popular.

\section{III.}

Nas duas primeiras partes deste texto eu tentei delinear três correntes de pensamento algo fantasiosas que me parecem permear o debate público brasileiro: as utopias da intervenção militar, da democracia 'direta' e a de uma democracia representativa extremamente idealizada. Esta última teria como pedra angular um Legislativo concebido à maneira aristotélica, isto é, dedicado ao "bem comum" e integrado só por gente honesta e intelectualmente bem preparada.

Frisei que essa visão da democracia representativa se torna utópica sobretudo por não se deter nas funções do Legislativo e 
na contínua disputa de poder que lhe é inerente. De fato, o que acontece num parlamento legislativo tem pouco a ver com um cotejo de ideias e muito a ver com confrontos de interesse. Se de uma dada eleição resultasse um legislativo só de sábios, os indivíduos e grupos teoricamente representados teriam muito com o que se preocupar, pois seria remota a chance de terem seus interesses adequadamente equacionados.

São vários, com efeito, os caminhos que levam à utopia. Não dando aos conceitos a atenção devida, o nosso hipotético cidadão comum muitas vezes presume (implicitamente, é claro) que as alternativas que os governos consideram em suas decisões são sempre ou em geral equivalentes: igualmente boas; não lhe passa pela cabeça que a escolha "normal" ou "típica" se dá entre alternativas ruins. Ruins do ponto de vista dos interesses envolvidos e ruins do ponto de vista de todos, ou seja, do "interesse geral" teoricamente corporificado no Estado.

Por que sempre entre alternativas ruins? Recordemos aqui uma premissa básica do argumento: o de que o processo de decisão política (em geral, embora aqui nos interesse o legislativo) é uma luta de poder. Todo projeto relevante contrapõe interesses e recursos de poder em cada etapa de sua tramitação. Inexiste praticamente a possibilidade de um dos contendores realizar $100 \%$ de seu objetivo (quero dizer, dos interesses que almeja transformar em lei, sejam eles materiais, religiosos, éticos etc). Para bem esclarecer este ponto, introduzirei aqui o conceito de trade-off, referente a "trocas" que inexoravelmente se impõem entre os objetivos dos diferentes contendores ou agentes políticos. Não tendo chance de realizar $100 \%$ de seu objetivo, cada contendor troca um pedaço dele pela aprovação do resto, sob pena de ficar sem nada. Lembremos um embate recente no Congresso brasileiro: o que se deu em torno do Código Florestal. Caricaturando um pouco, tratava-se de um embate entre pecuaristas e ambientalistas, os primeiros querendo a maior liberdade possível para organizar como lhes aprouvesse a abertura de pastagens na Amazônia, os 
segundos empenhados em evitar quanto possível o avanço da pecuária, ao ver deles uma séria ameaça à floresta.

Os pecuaristas adorariam escapulir a toda e qualquer restrição ambiental, os ambientalistas adorariam barrar pura e simplesmente a pecuária, a fim de preservar toda a mata. Alinhado de forma veemente com um dos lados, o nosso hipotético cidadão comum começa a sentir que o seu lado não consegue controlar a tramitação como ele esperava. A complicação parece não ter fim. Quanto mais ele imerge nessa avaliação, mais ele precisa de um bode expiatório para descarregar sua ira. Como "explicar" o imbróglio em que a coisa se transformou e a chance de a decisão final se afastar muito do que ele acha certo? Nem preciso dizer que, a esta altura, ele já está xingando os "políticos" (assim mesmo, entre aspas): "tem muita gente levando propina" etc etc. E os porcarias do governo, por que não agem? Pior ainda, por que às vezes eles agem a favor do outro lado?

Ou seja, explicar que é bom, ele não consegue. Por que não? Por três razões, creio eu. Primeiro, ele imagina que "o governo" ou "o Estado" é uma entidade onisciente e onipotente: não é uma coisa nem outra. Como regra geral, o governo procura determinar e impor um ponto de corte razoável entre os interesses em pugna, mas nem sempre consegue; seus recursos de poder são consideráveis, mas não a ponto de poder atropelar um ou os dois contendores. Segundo, o nosso cidadão não pensa no trade-off que o referido projeto implica. Os dois lados gostariam de obter uma quantidade tão próxima de $100 \%$ daquilo que estão buscando quanto possível. Gostariam, tudo bem, mas não vão alcançar, pela singela razão de que isso não é possível. A raiz do trade-off não são interesses escusos, a incompetência de tal ou qual partido, os equívocos do governo ou coisa que o valha. Tudo isso provavelmente interfere, ainda mais numa questão de tal magnitude, mas o que força cada lado a se contentar com uma parte apenas do que esperava obter é a realidade, pura e simplesmente. É a escassez relativa e o caráter indivisível do bem em disputa. A terra disponível é uma só. Uma parte da socie- 
dade quer o máximo possível de preservação ambiental, mas nem ela dispensa um bom filé; a pecuária quer liberdade para perseguir seu objetivo econômico, mas não pode desconhecer os riscos que um desmatamento indiscriminado representam para todo o país, e quiçá para o mundo. 0 governo também tem interesses em jogo: por exemplo, as divisas que a pecuária ajuda a obter, indispensáveis ao balanço de pagamentos com o exterior.

Das duas primeiras resulta uma terceira casca de banana que o nosso cidadão médio raramente consegue evitar. Não querendo admitir as restrições que a realidade impõe - desde logo a impossibilidade de satisfazer plenamente todos os interesses envolvidos - ele acaba impugnando como ilegítimas a pluralidade de interesses que existe na sociedade e a democracia, esse arcabouço institucional que os acolhe e expressa na esfera política. Pode até admiti-las intelectualmente, mas recalcitra no coração. No fundo, para ele, "legítimo sou eu, ora bolas, não o meu adversário". Acabei me estendendo demais neste trecho. Quero ainda dizer algo sobre as manifestações de junho, sobre a reforma política sugerida pela presidente e outros possíveis caminhos para melhorar o sistema político.

IV.

Esta é a quarta e última parte desta série "labirintos". Direi inicialmente alguma coisa sobre as manifestações de junho, passarei em seguida a algumas considerações de ordem geral sobre a reforma política e concluirei com uma breve explanação a respeito do sistema eleitoral.

\section{Interpretando a "voz das ruas"}

É obviamente muito difícil dizer se protestos daquele tipo voltarão a acontecer no futuro; de igual intensidade, provavelmente não, mas o prognóstico mais seguro parece-me ser o de que 
eles reaparecerão de tempos em tempos. Primeiro, porque suas causas não desapareceram nem vão desaparecer tão cedo; segundo, porque através deles uma parcela enorme da sociedade brasileira se apropriou de uma tecnologia política, a mobilização via internet, sem uma fisionomia definida, como na "primavera árabe"; terceiro porque eles foram amplamente aprovados pela sociedade, não obstante os episódios de vandalismo e violência. A pesquisa CNT divulgada hoje (16.07.13), baseada em uma amostra nacional, registrou um índice de aprovação da ordem de 83\%.

Muito se especulou sobre as razões e os alvos do protesto. 0 que os motivou foi "só" o bolso (tarifa do transporte, inflação etc.) ou também o mau desempenho do sistema político: das autoridades atuais e do arcabouço através do qual elas chegaram às posições de poder que hoje ocupam?

Não vejo utilidade em retomar essa discussão a partir do ponto zero. Dou por assentado que as manifestações vocalizaram uma demanda substantiva (econômica e social) e também uma de caráter político e institucional. Tentarei interpretá-las e apontar alguns importantes pontos de contato entre elas.

A demanda substantiva parece-me ter sido bem do tipo "farinha pouca, meu pirão primeiro". Indignada com o nível da corrupção, os desmandos cometidos quase diariamente por agentes dos três Poderes e o desatinado padrão de investimentos do governo federal (os referentes à Copa, em particular), uma grande parcela da sociedade resolveu examinar com mais atenção e severidade o que tem recebido em termos de renda e de contrapartida em serviços públicos pelo que paga de impostos. A redução da taxa de crescimento da economia e a subida da inflação certamente aguçou-lhe a curiosidade, e ela não gostou do que viu. Percebeu, por um lado, que a farinha é pouca e está com cara de diminuir; pelo outro, que sua passividade manda para o sistema político um sinal errôneo de indiferença ou concordância com a rotina de barbaridades que se instaurou no país de alguns anos para cá. 
Farinha pouca? Ah, então não. Assim, valendo-se das manifestações, a sociedade avisou que quer receber a "substância" que lhe é devida agora e não num prazo indefinido. Traduzido para o léxico político, este aviso significa que ela retirou uma parte da confiança ou legitimidade que outorgava ao governo - ou seja, às autoridades em geral e às instituições políticas. Já não confiando tanto no governo, ela, a sociedade, encurtou os prazos e o colocou contra a parede.

Para trazer a legitimidade de volta a um nível que lhe pareça adequado, o governo tem que mostrar serviço. Mas "mostrar serviço" significa o quê, exatamente? Digamos que significa pagar uma parcela razoável de sua dívida, ou de suas dívidas, porque são duas: uma substantiva (social) e outra institucional (política). É aqui que entra a desastrada proposta dos cinco pactos feita pela presidente Dilma naquela aparição em rede nacional de rádio e TV.

Para pagar a dívida social, o que ela tinha a oferecer era muito pouco, e ela mesma cuidou de piorar as coisas ao anunciar a decisão de importar médicos. Pelo lado político, o que se viu foi uma inacreditável série de disparates: ela pediria ao Congresso (ao qual cabe tal autoridade) para convocar um plebiscito pelo qual os eleitores autorizariam a convocação de uma Constituinte com mandato específico para realizar uma reforma política. Para os que me leem, está bom assim ou querem mais? Ah sim, há mais um ponto: Dilma queria (ou quer, sei lá) que a reforma política valesse ou valha já a partir de 2014. Não foi a toa que eu dei a esta série de textos o título "labirintos, tergiversações e enganações".

Só uns poucos acólitos viram o "pacto pela reforma política" como uma resposta adequada ao clamor das ruas. Na imprensa, a avaliação dos comentaristas foi maciçamente no sentido contrário. Os que nele discerniram alguma esperteza entenderam-no como tergiversação ou enganação; muitos nem isso lhe concederam. 
Voltemos porém às ruas: é realmente possível afirmar que elas articularam um conteúdo institucional, vale dizer, uma demanda de reforma política? Admitamos que sim, que algo foi sinalizado nessa direção, não vindo ao caso discutir aqui a intensidade ou o grau de elaboração conceitual de que tal demanda se revestiu. Alguma coisa se disse no tocante aos "métodos" atuais de se fazer política; um nível mais alto de probidade certamente foi exigido; e muitos tópicos específicos como voto distrital e financiamento público foram ocasionalmente mencionados.

No day after, à luz das pesquisas de intenção de voto, o tema dominante nas discussões foi se o alvo dos protestos havia sido toda a classe política, sem discriminações, ou mais a presidente da República e o PT. Mas as questões que importam para os fins deste texto são outras, como espero mostrar em seguida.

Desde a mencionada peroração televisiva de Dilma Rousseff, o meio político e a mídia entraram na discussão da reforma sem atentar suficientemente para dois pressupostos assaz problemáticos.

Primeiro, o de que os objetivos desejados podem ser satisfatoriamente alcançados por meio de uma reforma política formal -de uma "engenharia institucional", se se prefere- e dentro de um prazo relativamente curto. Trata-se de uma meia verdade.

Segundo, o de que a questão está mais que esclarecida, e que as razões e objetivos de uma eventual reforma, assim como as relações de causa e efeito entre os diversos mecanismos do sistema político são sobejamente conhecidos (tanto assim que se fala em plebiscito...). Outra meia verdade, se não forem afirmações decididamente falsas.

As manifestações, como observei acima, podem e devem ser entendidas como uma retirada pela sociedade de uma parte da legitimidade que ela antes outorgava ao sistema político. Pois 
bem: essa parte que ela se negou a manter, foi retirada do regime democrático-representativo como tal? Se sim, em proveito de que outro modelo? Se não foi tomada ao regime, então evidentemente o foi às autoridades; mas só dos indivíduos investidos em funções de autoridade ou também aos mecanismos mediante os quais elas ascenderam a tais funções - ou seja, à estrutura de partidos, ao sistema eleitoral e à federação, entre outros?

Os leitores haverão de me perdoar por toda esta escolástica e pelo caráter repetitivo de minha argumentação, mas prefiro pecar por excesso: o tema é sério demais para ser tratado por alto. Senão vejamos.

A quem acredita que a legitimidade foi [irreversivelmente] negada ao regime democrático-representativo como tal, tudo o que eu posso dizer é que não perca tempo discutindo reforma política. Nessa ótica não se trata de reforma e sim de intervenção militar ou revolução, assuntos discutidos na primeira parte desta série.

Se a legitimidade não foi negada ao próprio regime, ou se o foi de forma reversível, a questão a frisar é que não há como considerá-la isoladamente; todo sistema político e todo projeto de reforma digno deste nome persegue vários objetivos ao mesmo tempo. Pelo menos três, eu diria: a legitimidade, a eficiência e a estabilidade (prevenção de crises e rupturas). São objetivos diferentes, mas profundamente interligados. Por exemplo, a eficiência (do governo, da máquina administrativa) tem tudo a ver com a satisfação das demandas sociais e com o próprio crescimento econômico, os quais repercutem sobre a legitimidade, reforçando-a ou solapando-a. Uma redução acentuada nos níveis de eficiência e legitimidade pode ensejar tensões e crises capazes de colocar em risco a própria estabilidade do regime, ou seja, levando-o à iminência da ruptura constitucional, ou de fato provocando-a. Em abstrato estes três objetivos ou requisitos são compatíveis, mas esta avaliação deve ser feita em concreto, em vista do tipo de reforma que se pretende implantar, bem como da forma e do ritmo de sua implantação. 
A eficiência tem a ver com a presteza, a qualidade e o custo de todos os bens e serviços que o Executivo presta à sociedade, mas tampouco deve ser entendido como um valor absoluto, a ser perseguido sem atenção aos outros dois. Na democracia representativa, tentar realizá-lo certamente NÃO implica entregar um cheque em branco a quem quer que seja; não significa autorização para atropelar o Congresso e impor um "executivismo" ’̀ outrance. Muito pelo contrário, uma reforma política democrática deve procurar meios para evitar um predomínio exagerado do Executivo sobre o Legislativo etc., permitindo que este se desincumba de suas funções com altivez, autonomia e iniciativa. Soa óbvio, bem o sei, mas as discussões sobre "governabilidade" quase sempre caminham na direção contrária.

\section{O ponto chave da reforma}

Entre os pontos a considerar na reforma- quer ela seja feita via plebiscito ou por um projeto do Legislativo submetido a referendo popular- o que me parece mais importante é o sistema eleitoral.

Obviamente, não há sistema eleitoral perfeito, cada um maximiza um determinado aspecto, implicando vantagens e desvantagens. Consenso não existe sequer entre os cientistas políticos versados na matéria, que é de fato bastante técnica. No Brasil, os partidos de esquerda, os pequenos partidos, a esquerda intelectualizada e os chamados "movimentos sociais" (satelitizados pela esquerda) tradicionalmente defendem a manutenção do sistema vigente, uma modalidade de representação proporcional; defendem-na em parte por ideologia (a propalada "proteção às minorias") e em parte por desconhecimento das possíveis alternativas.

As alternativas geralmente consideradas são o voto distrital na versão "pura" (norte-americana) ou "mista" (alemã); deixo estes termos entre aspas para advertir que não traduzem adequada- 
mente o sentido técnico dos respectivos conceitos. No distrital "puro", o país é dividido em tantos distritos quantas as cadeiras a preencher na Câmara, e cada distrito elege um e somente um deputado; daí ser esse sistema tecnicamente intitulado "majoritário uninominal". 0 sistema ser majoritário significa que um candidato se elege, e os votos do outro ou dos outros são "esterilizados", vale dizer, não geram nenhuma representação. Os doutrinadores de esquerda geralmente se apegam a este aspecto e sentenciam tratar-se de um sistema incompatível com a democracia. Este argumento tem a curiosa propriedade de colocar os Estados Unidos, a Inglaterra e os demais países da Commonwealth quase na lata de lixo das não-democracias e de alçar o Brasil, não direi aos píncaros, mas para uma posição invejável no que tange a seu grau de "democraticidade".

O sistema misto alemão- ao contrário de uma opinião bastante difundida- NÃO é majoritário no sentido acima; ele se vale de um mecanismo distrital-majoritário para preencher metade das cadeiras, mas o sistema em seu conjunto funciona de acordo com o princípio da proporcionalidade. Assim como o norte-americano, este também é às vezes considerado incompatível com a democracia, avaliação que coloca a Alemanha na situação dos países de língua inglesa do parágrafo anterior.

(As quatro partes desse artigo foram escritos em julho de 2013).

Recebido em 10.09.2013

Aprovado em 15.10.2013 